\title{
Plasma pro-atrial natriuretic peptide to estimate fluid balance during open and robot-assisted esophagectomy: a prospective observational study
}

Rune Broni Strandby ${ }^{1 *}$, Rikard Ambrus ${ }^{1}$, Niels H. Secher ${ }^{2}$, Jens Peter Goetze ${ }^{3}$, Michael Patrick Achiam ${ }^{1}$ and Lars Bo Svendsen ${ }^{1}$

\begin{abstract}
Background: It remains debated how much fluid should be administered during surgery. The atrial natriuretic peptide precursor proANP is released by atrial distension and deviations in plasma proANP are reported associated with perioperative fluid balance. We hypothesized that plasma proANP would decrease when the central blood volume is compromised during the abdominal part of robot-assisted hybrid (RE) esophagectomy and that a positive fluid balance would be required to maintain plasma proANP.
\end{abstract}

Methods: Patients undergoing RE $(n=25)$ or open $(\mathrm{OE} ; n=25)$ esophagectomy for gastroesophageal cancer were included consecutively in this prospective observational study. Plasma proANP was determined repetitively during esophagectomy to allow for distinction between the abdominal and thoracic part of the procedure. The RE group was $15^{\circ}$ head up tilted during the abdominal procedure.

Results: The blood loss was 250 (150-375) (RE) and $600 \mathrm{ml}$ (390-855) (OE) ( $p=0.01)$, but the two groups of patients were provided with a similar positive fluid balance: 1705 (1390-1983) vs. $1528 \mathrm{ml}(1316-1834)(p=0.4)$. However, plasma proANP decreased by $21 \%(p<0.01)$ during the abdominal part of RE carried out during moderate head-up tilt, but only by $11 \%(p=0.01)$ during OE where the patients were supine. Plasma proANP and fluid balance were correlated in the RE-group $(r=0.5(0.073-0.840), p=0.02)$ and tended to correlate in the OE group $(r=0.4(-0.045-0.833), p=0.08)$.

Conclusion: The results support that plasma proANP decreases when the central blood volume is compromised and suggest that an about $2200 \mathrm{ml}$ surplus administration of crystalloid is required to maintain plasma proANP during esophagectomy.

Trial registration: Clinicaltrials.gov (NCT02077673). Registered retrospectively February $12^{\text {th }} 2014$.

Keywords: Central blood volume, Abdominal surgery, Fluid balance, Plasma-atrial natriuretic peptide

\footnotetext{
* Correspondence: rune.broni.strandby.01@regionh.dk

'Department of Surgical Gastroenterology, University of Copenhagen,

Rigshospitalet, Blegdamsvej 9, DK-2100 Copenhagen- $\varnothing$, Denmark

Full list of author information is available at the end of the article
} 


\section{Background}

Fluid administration affects outcome after surgery [1-3], but it remains debated how much fluid should be administered and how the volume load is to be evaluated $[4,5]$. For colorectal surgery a "restricted" fluid regimen seems profitable in regard to cardiopulmonary complications and tissue healing $[3,6]$. On the other hand, patients going through laparoscopic cholecystectomy appear to benefit from a "liberal" fluid regimen [1], probably because the patients are head-up tilted. Deviations in postoperative outcome relate likely to how well the central blood volume (CBV) is maintained during surgery. Consequently, so-called individual goal-directed fluid therapy aims at maintaining a CBV that does not limit, e.g. stroke volume (SV) during surgery, eventually based on a report of SV by minimally invasive apparatus [5, 7].

We considered that plasma atrial natriuretic peptide (ANP) would indicate whether filling of the heart is maintained during surgery. ANP - but not "brain" natriuretic peptide [8] - reacts rapidly to a reduction in CBV, e.g. during head-up tilt [9] or sitting or standing up [8] as with pressure breathing [10] demonstrating independence of even a large increase in central venous pressure [11]. Compared to plasma ANP, plasma pro-ANP (proANP) is stable with a half-life of 60-120 min [12] and during cystectomy, plasma proANP decreases with the perioperative blood loss and, conversely increases with a positive fluid balance when administration is based mainly on lactated Ringer's solution (LR) [13].

We determined plasma proANP and perioperative fluid balance during open (OE) and robot-assisted hybrid (RE) esophagectomy. During esophagectomy CBV could be compromised not only by an eventual blood loss but also by, e.g. epidural analgesia during $\mathrm{OE}$ and head-up tilt and abdominal $\mathrm{CO}_{2}$ insufflation during RE. We hypothesized that plasma proANP would decrease when $\mathrm{CBV}$ is compromised during the abdominal part of RE and that a positive fluid balance would be required to maintain plasma proANP when fluid administration is based mainly on LR.

\section{Methods}

This prospective non-randomized study was a secondary data analysis of a clinical trial directed to monitor gastric microcirculation during $\mathrm{RE}$ and $\mathrm{OE}$ esophagectomy (ClinicalTrials.gov, ID: NCT02077673) [14] as approved by the Scientific Ethical Committees, Capital Region, Denmark (H-2-2013-101). Patients were consecutively included between December 2013 and April 2015. Oral and written informed consent was provided at least 1 day before surgery. All patients with biopsy verified adenocarcinoma of the gastroesophageal junction eligible for a two-stage procedure with an abdominal and a thoracic part (Ivor Lewis esophagectomy) [15] were candidates for the study (Table 1). Data were collected by the investigators and remained confidential throughout the trial. Patients were excluded from the study if consent was withdrawn or disseminated disease was evident, i.e. only patients for whom the operation was completed were included.

\section{Anesthesia and interventions}

An i.v. line was established followed by a thoracic epidural catheter (Th7-Th9) and its position was evaluated with the response to administration of $3 \mathrm{ml} \mathrm{2 \%}$ lidocaine with adrenaline (SAD, Amgros I/S, Denmark). Induction of anesthesia was with propofol $(2.0 \mathrm{mg} / \mathrm{kg})$ and remifentanil $(0.5 \mu \mathrm{g} / \mathrm{kg})$ followed by placement of a doublelumen endobronchial tube after neuromuscular blockade by cisatracurium. Anesthesia was maintained by propofol $(5-10 \mathrm{mg} / \mathrm{kg} / \mathrm{h})$ and remifentanil $(1.75-2.25 \mathrm{mg} / \mathrm{h})$ and ventilation was adjusted to an end-tidal $\mathrm{CO}_{2}$ tension of 28-32 mmHg (Dräger CATO; M32040, Lübeck, Germany). Guided by ultrasound a central venous catheter was established via the right jugular vein for infusion of fluids and, if considered necessary vasopressors (Table 2$)$. LR (3 ml/kg/ h) was supplemented by $5 \%$ Voluven $^{\bullet}$ or human albumin $5 \%$ if considered in need by the anesthesiologist. Red blood cells were administered when hemoglobin was lower than 4.5 or $5.5 \mathrm{mmol} / \mathrm{l}$ if the patient was known with cardiopulmonary disease. For epidural anesthesia $4 \mathrm{ml}$ bupivacaine $(5 \mathrm{mg} / \mathrm{ml}, \mathrm{SAD})$ was administered before start of the procedure in both groups. Analgesia was maintained with bupivacaine $(4 \mathrm{ml} / \mathrm{h}$ ) with morphine (comb. $2.5 \mathrm{mg}$ and 50 microgram/ml, SAD, Amgros I/S, Denmark) before start of

Table 1 Patient characteristics for patients undergoing robotassisted hybrid (RE) or open esophagectomy (OE)

\begin{tabular}{lllc}
\hline & $\mathrm{RE}(n=25)$ & $\mathrm{OE}(n=25)$ & $P$-value \\
\hline Age, years & $64.8( \pm 10.4)$ & $68( \pm 7.9)$ & 0.1 \\
Male sex, $n(\%)$ & $22(88.0)$ & $20(80.0)$ & 0.5 \\
$\mathrm{BMI}, \mathrm{kg} / \mathrm{m}^{2}$ & $25.2( \pm 3.3)$ & $25.8( \pm 5.1)$ & 0.15 \\
Alcohol, earlier abuse, $n(\%)$ & $3(12.0)$ & $2(8.0)$ & 1.0 \\
Tobacco, current \& former, $n(\%)$ & $22(88.0)$ & $22(88.0)$ & 1.0 \\
ASA-classification $\geq 3, n(\%)$ & $5(20.0)$ & $12(48)$ & 0.04 \\
Hypercholesterolemia, $n(\%)$ & $1(4.0)$ & $7(28.0)$ & 0.03 \\
Hypertension, $n(\%)$ & $10(40.0)$ & $12(48.0)$ & 0.6 \\
Diabetes, $n(\%)$ & $5(20.0)$ & $8(32.0)$ & 0.4 \\
Heart disease, $n(\%)$ & $1(4.0)$ & $3(12.0)$ & 0.7 \\
Pulmonary disease, $n(\%)$ & $1(4.0)$ & $5(20.0)$ & 0.1 \\
Duration of procedure, minutes & $254( \pm 34.0)$ & $239( \pm 41.0)$ & 0.9 \\
LOS, days & $13( \pm 7.0)$ & $15( \pm 8.0)$ & 0.3 \\
\hline BM body mass & &
\end{tabular}

$B M I$ body mass index, ASA American Society of Anesthesiologists classification, LOS length of hospital stay. Heart disease: ischemic heart disease, arrhythmias, and valve insufficiency. $P$-values by univariate analyses. Values are mean with standard deviation (SD) unless stated otherwise 
Table 2 Perioperative fluid administration during open (OE) and robot-assisted esophagectomy (RE)

\begin{tabular}{|c|c|c|c|}
\hline & $\mathrm{OE}(n=25)$ & $\operatorname{RE}(n=25)$ & $P$-value \\
\hline Fluid administration, $\mathrm{ml}^{\mathrm{a}}$ & $2600(2400-3166)$ & $2500(2150-2825)$ & 0.2 \\
\hline Electrolytes, ml ${ }^{b}$ & $1993(1725-2475)$ & $2000(1700-2300)$ & 0.7 \\
\hline $\begin{array}{l}\text { Human albumin, Voluven } \\
\& \text { PRBC, ml }\end{array}$ & $500(500-938)$ & $500(250-750)$ & 0.2 \\
\hline Ephedrine, mg & $2.5(0-14)$ & $5.0(0-13)$ & 0.9 \\
\hline Phenylephrine, mg & $0.1(0-0.3)$ & $0.2(0-0.4)$ & 0.9 \\
\hline $\begin{array}{l}\text { Vasopressor infusion, } \\
\mathrm{ml} / \mathrm{min}\end{array}$ & $0.14(0.1-0.2)$ & $0.12(0.1-0.2)$ & 0.6 \\
\hline Fluid loss, $\mathrm{ml}^{\mathrm{c}}$ & 1018 (839-1345) & $655(445-1065)$ & 0.01 \\
\hline Blood loss, ml & $600(390-855)$ & $250(150-375)$ & 0.01 \\
\hline Diuresis, ml & $410(296-599)$ & $345(300-490)$ & 0.5 \\
\hline Fluid balance, $\mathrm{ml}^{\mathrm{d}}$ & 1528 (1316-1834) & 1705 (1390-1983) & 0.4 \\
\hline
\end{tabular}

Values are medians with interquartile range. $P$-values by Mann-Whitney U-test. ${ }^{\text {a }}$ Fluid administered during anesthesia including medicine and packed red blood cells (PRBC), bprimarily lactated Ringer's solution, ' Fluid loss = diuresis and blood loss, ${ }^{\mathrm{d}}$ Fluid balance $=$ fluid infusion - fluid loss. For vasopressor infusion norepinephrine or phenylephrine were used

laparotomy in the OE-group and before the thoracotomy in the RE-group.

The OE patients were supine during the abdominal part of the procedure while RE patients were tilted $15^{\circ}$ head-up for use of a da Vinci System (5.0 robotic, Intuitive Surgical Inc., Sunnyvale, CA, USA). The thoracotomy was on the right side in left-lateral decubitus position.

Heart rate (HR), SV, mean arterial pressure (MAP), cardiac output (CO), and systemic vascular resistance (SVR) were monitored by modified Model flow technology (Nexfin ${ }^{\oplus}$ BMEYE B.V., Amsterdam, The Netherlands) through a radial artery catheter in the non-dominant arm [16]. Markers in the Nexfin file were: A after induction of anesthesia (baseline); B following laparotomy (OE) or pneumoperitoneum (RE); C 15 min after start of the procedure; D after mobilization of the stomach, and $\mathrm{E}$ following abdominal closure (OE) or $\mathrm{CO}_{2}$ desufflation (RE); $\mathrm{F}$ following the gastric remnant pull to the thorax; $\mathrm{G}$ formation of the anastomosis, and $\mathrm{H}$ following closure of the thorax. Also, arterial blood samples were obtained at each of these events for determination of plasma proANP. The samples were centrifuged at $3000 \mathrm{rpm}$ for $10 \mathrm{~min}$ at $4{ }^{\circ} \mathrm{C}$ and plasma stored at $-80^{\circ} \mathrm{C}$ until analysis.

Fluid balance was calculated following closure of the thorax: LR, human albumin $5 \%$, Voluven ${ }^{\circ}$, packed red blood cells, and medicine vs. the blood loss and diuresis. Also, a separate balance for colloid and crystalloids was estimated.

\section{Plasma proANP}

Plasma proANP was measured with an automated method from Thermo-Fisher (the Kryptor Plus platform) that directs antibodies against epitopes within the mid- region of the precursor [17] and is validated with excellent performance in non-heart failure patients against a gold standard immunoassay [18-20].

\section{Statistics}

Statistics was carried out by IBM SPSS ${ }^{\circ}$ version 22.0.0 (SPSS, Inc., IL, USA) and graphs constructed (Graph Pad Software Inc., CA, USA). Baseline characteristics were evaluated with chi-square or Fisher's exact test for nominal variables and $t$-test and Mann-Whitney U-test for continuous variables depending on whether data were normally distributed. To assess changes in plasma proANP vs. fluid balance linear regression analysis was used. Changes in hemodynamic variables and in plasma proANP during surgery were analyzed using the Friedman's test. Post hoc comparisons with Bonferroni correction were applied if the initial test was significant. Values are expressed as mean with standard deviation or medians with interquartile range (IR) and a $p$-value $\leq 0.05$ was considered statistical significant.

\section{Results}

For RE 25 patients were enrolled consecutively and there were 26 patients in the OE-group, but one OE patient was excluded because the procedure was changed to total gastrectomy. Patients in the $\mathrm{OE}$ group demonstrated a higher ASA-score $\geq 3(p=0.04)$ and a higher prevalence of hypercholesterolemia $(p=0.03)$ (Table 1).

\section{Fluid balance and hemodynamics}

The intraoperative blood loss was $250 \mathrm{ml}$ (150-375 IR) in the RE-group and $600 \mathrm{ml}(390-855)$ during OE $(p=0.01)$, while fluid administration was similar (2500 (2150-2825) and $2600 \mathrm{ml}$ (2400-3166), respectively) ( $p=0.20$, Table 2 ). Thus, the fluid balance was positive by 1705 (1390-1983) (RE) and $1528 \mathrm{ml}$ (1316-1834) (OE), $p=0.40$.

Hemodynamic variables during the procedures are presented in Fig. 1. In the RE-group $\mathrm{CO}(p=0.02)$ and HR $(p<0.01)$ increased from induction of pneumoperitoneum (B) to mobilization of the stomach (D). Meanwhile SV decreased $(p<0.01)$ and SVR increased after pneumoperitoneum was established $(p=0.04)$ but returned to baseline $15 \mathrm{~min}$ after start of the procedure $(C)(p=0.04)$ at a stable MAP $(p=1.00)$. Following $\mathrm{CO}_{2}$ desufflation (E) and termination of head-up tilt, MAP $(p=0.02)$, SV $(p<$ $0.01)$, and $\mathrm{CO}(p<0.01)$ increased while HR decreased $(p$ $=0.01)$ leaving SVR stable $(p=1.00)$. During the thoracic part of the procedure MAP $(p=0.05), \mathrm{CO}(p<0.01)$, SV $(p=0.04)$, and HR $(p=0.02)$ decreased towards baseline levels, while SVR was stable $(p=0.31)$. However, SV $(p=$ $0.01)$ increased following closure of the thorax.

During OE, HR $(p<0.01), \mathrm{SV}(p=0.05)$ and thus CO $(p<0.01)$ increased from baseline (A) to 15 min after start of the procedure $(\mathrm{C})$. MAP remained stable $(p=0.70)$ and 


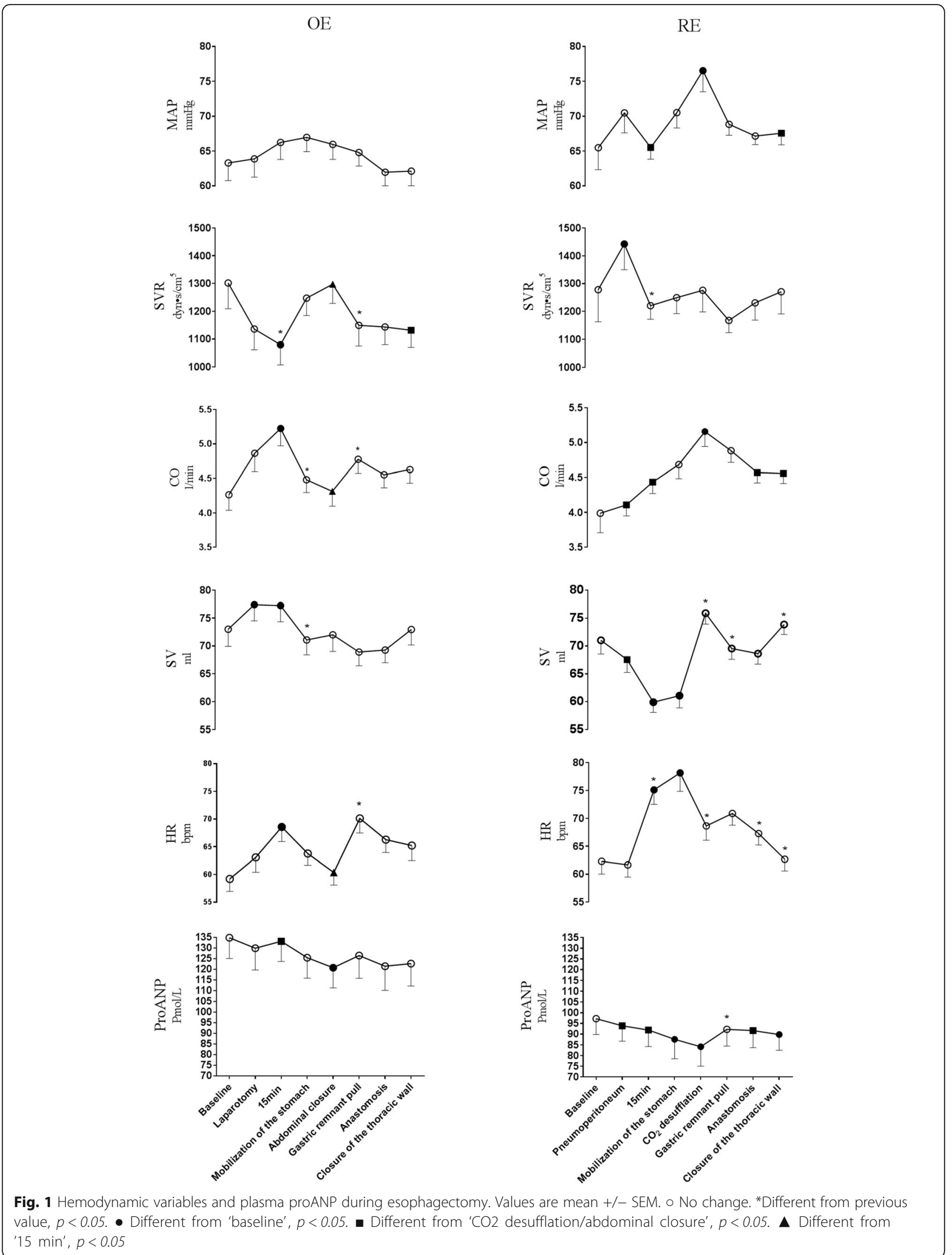


hence SVR decreased $(p=0.02)$. By abdominal closure HR $(p=0.02), \mathrm{CO}(p<0.01)$, and SV $(p=0.18)$ decreased towards baseline levels. MAP $(p=0.73)$ was stable and therefore SVR increased $(p=0.01)$. During the thoracic part of the procedure SVR $(p=0.01)$ decreased by gastric remnant pull with a concomitant increase in $\mathrm{HR}(p<0.01)$ and $\mathrm{CO}(p<0.01)$. Hemodynamic variables remained at these levels until closure of the thorax. There was no significant difference in vasopressor administration between the two groups of patients (Table 2).

\section{Plasma proANP}

In the OE-group plasma proANP decreased by $11 \%$ ( $p=$ 0.01 ) during the abdominal part of the procedure, but by $21 \%$ in the RE-group $(p<0.01)$. During the thoracic part of the procedure plasma proANP remained stable in the OE-group $(p=1.00)$, but increased in the RE-group from $\mathrm{CO}_{2}$ desufflation (E) to gastric remnant pull (F) $(p=$ 0.01) (Table 3 and Fig. 1). However, plasma proANP was lower at thoracic closure $(\mathrm{H})$ than at baseline $(\mathrm{A})$ in the RE-group $(p=0.01)$. Linear regression between plasma proANP and fluid balance showed an $r$-value of 0.4 $((-0.045-0.833), p=0.08)$ in the OE-group and 0.5 ((0.073-0.840), $p=0.02)$ for the RE patients (Fig. 2).

\section{Discussion}

Plasma proANP was determined repetitively during surgery to allow for a distinction between the abdominal and thoracic part of Ivor Lewis esophagectomy for which CBV could be compromised by the head-up tilt used for the abdominal part of the robot-assisted procedure $[11,21]$. In fact, plasma proANP decreased twice as much during the abdominal part of RE (by 21\%) than during OE (by $11 \%)$ despite fluid balance was positive by about $1700 \mathrm{ml}$ (by the end of surgery) in both groups and the blood loss

Table 3 Plasma proANP during robot-assisted (RE) and open esophagectomy (OE)

\begin{tabular}{lll}
\hline & $\mathrm{RE}(\mathrm{pmol} / \mathrm{L}, n=25)$ & $\mathrm{OE}(\mathrm{pmol} / \mathrm{L}, n=25)$ \\
\hline Baseline & $95(64-125)$ & $135(102-161)$ \\
$\begin{array}{l}\text { Pneumoperitoneum/ } \\
\text { Laparotomy }\end{array}$ & $91(60-119)$ & $118(94-168)$ \\
15 min after start of procedure & $83(59-114)$ & $133(96-173)$ \\
$\begin{array}{l}\text { Mobilization of the stomach } \\
\mathrm{CO}_{2} \text { desufflation/abdominal }\end{array}$ & $81(55-102)$ & $123(95-158)$ \\
$\begin{array}{l}\text { Closure } \\
\text { Gastric remnant pull }\end{array}$ & $89(58-99)^{\mathrm{a}}$ & $120(82-157)^{\mathrm{b}}$ \\
Anastomosis & $87(57-122)$ & $115(88-158)$ \\
Closure of the thorax & $85(56-119)^{\mathrm{b}}$ & $101(78-157)$
\end{tabular}

Values are medians with interquartile range. $P$-values by Friedman's test

${ }^{a} p<0.01$ different from baseline within the group

${ }^{\mathrm{b}} p=0.01$ different from baseline within the group

${ }^{c} p=0.01$ different from ' $\mathrm{CO}_{2}$ desufflation' within the group
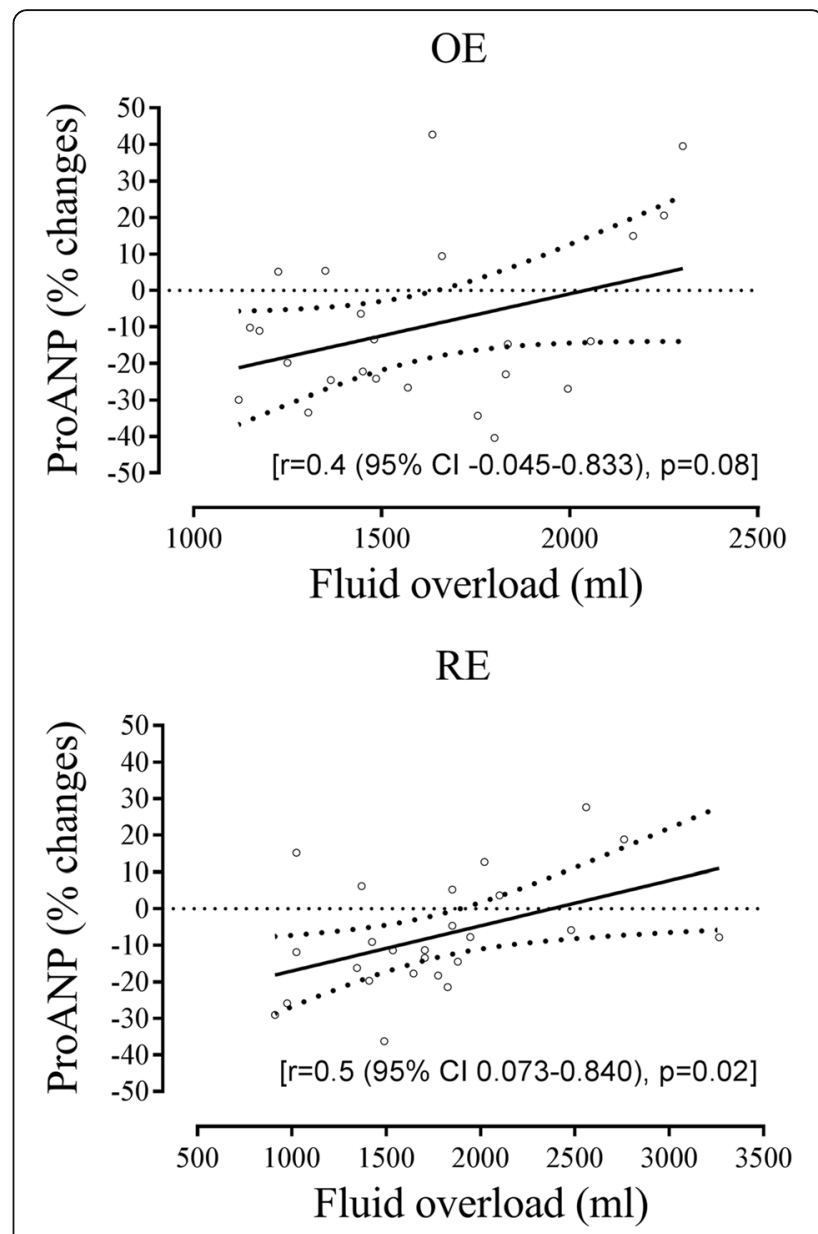

Fig. 2 Plasma ProANP in relation to fluid balance during open (OE) and robot assisted esophagectomy (RE). Change in plasma proANP from start (baseline) to end of surgery (closure of the thorax). Regression line with $95 \% \mathrm{Cl}$. Horisontal broken line indicates no change in proANP

largest during $\mathrm{OE}(600$ vs. $250 \mathrm{ml})$. Furthermore, plasma proANP, MAP, and CO increased while HR decreased after $\mathrm{CO}_{2}$ desufflation and termination of head-up tilt. Together, these observations support that CBV is reduced during surgery and especially so if there is a restrain on venous return to the heart by head-up tilt and abdominal $\mathrm{CO}_{2}$ insufflation.

The ratio between the interstitial fluid space and plasma is about $1: 5$ and it is assumed that only $20-25 \%$ of the administered LR remains in plasma $[22,23]$ and a separate calculation for the administered crystalloid and colloid was conducted (Table 2). If $25 \%$ of the administered $2000 \mathrm{ml}$ of LR is taken to remain within the vessels together with $5 \%$ albumin/voluven ${ }^{\circ}$ and red blood cells, the intravascular fluid balance would be $+350 \mathrm{ml}$ in the RE-group and $-20 \mathrm{ml}$ for the OE-group. Thus, the patients were on average close to "normovolemic" by the end of surgery supported by stable hemodynamic variables during the thoracic procedure and increasing plasma proANP 
(Table 3). Yet, from determination of plasma proANP, the patients seemed functional hypovolemic during the abdominal part of the procedure and more so in the REgroup that was exposed to head-up tilt combined with pneumoperitoneum. Thus, plasma proANP normalized when the RE patients were prepared for thoracic surgery, although plasma proANP did not reach the baseline value. In a similar study, plasma proANP was followed during open (ORC) and robot-assisted cystectomy (RARC) [13]. Plasma proANP decreased by $23 \%$ in the ORC-group with a $1500 \mathrm{ml}$ positive fluid balance. Furthermore, plasma proANP correlated to fluid balance. Also, plasma proANP did not change for the RARC group, probably reflecting that the patients were head-down tilted and the blood loss was minimal.

As estimated by linear regression, a positive fluid balance by approximately 2400 (RE) and $2000 \mathrm{ml}(\mathrm{OE})$ seemed to be required to keep plasma proANP stable during surgery (Fig. 2), i.e. approximately $600 \mathrm{ml}$ more than was administered. Similarly for patients undergoing laparoscopic cholecystectomies in a head-up tilted position [1], improvement was found for pulmonary function, exercise capacity, nausea, and dizziness for patients administered $40 \mathrm{ml} / \mathrm{kg}$ LR (approx. $3000 \mathrm{ml}$ ) compared to $15 \mathrm{ml} / \mathrm{kg}$ (approx. $1000 \mathrm{ml}$ ). Yet, it remains to be determined whether more fluid should be administered during head-up tilted major abdominal procedures to prevent functional hypovolemia, i.e. whether it favors outcome including microcirculation to the anastomotic area and reduction in hypotensive episodes during surgery. On the other hand, excess fluid administration can lead to interstitial edema, impaired tissue healing with impact of anastomotic healing and also cardiopulmonary complications representing a risk factor $[3,24,25]$.

Epidural anesthesia reduces SVR [26] due to sympatholysis as observed in the OE-group while SVR remained stable in the RE-group, besides a transitory increase may be due to $\mathrm{CO}_{2}$ insufflation with release of hormones like noradrenalin, compression of the splanchnic organs, and $\mathrm{CO}_{2}$ absorbed from the peritoneal cavity $[27,28]$. Moreover, traction of the viscera can stimulate release of vasoactive hormones like prostacyclin corroborating a decrease in SVR, more prevalent during open than laparoscopic surgery [29-31].

This study was based on a secondary analysis of prospective data in a non-randomized design and selection bias should be considered. The two groups of patients demonstrated different baseline plasma proANP (Table 3) maybe related to that the ASA score was higher in the OE group and not acknowledged heart disease may have been overrepresented [32] supported by a higher prevalence of hypercholesterolemia. Thus, we cannot rule out that patients presenting co-morbidity have been selected for the "conservative" OE procedure although the primary criterion for selection of $\mathrm{OE}$ or $\mathrm{RE}$ was based on the access to the da Vinci System.

We accept that this report is only the second to evaluate fluid balance during surgery in relation to plasma proANP and that a wider database is needed to guide inter-operative fluid therapy on its influence on plasma proANP. However, we find it of interest to add a biomarker to evaluation of perioperative fluid balance presently mainly based on a predefined fluid regime supplemented by recording of physiological variables. Furthermore, we acknowledge that other measures of $\mathrm{CO}$ like transesophageal echocardiography [33], thoracic electrical impedance [34], and central venous oxygen saturation [35] can be obtained for assessment of CBV and may be required to generalize the findings of this study.

\section{Conclusion}

This study showed a marked decrease in plasma proANP during the abdominal part of esophagectomy supporting that CBV is compromised during surgery and especially so for laparoscopic procedures including head-up tilt. We demonstrated a correlation between plasma proANP and perioperative fluid balance based mainly on LR. Taking plasma proANP to indicate filling of the heart, the data support that plasma proANP is a marker of fluid balance during surgery. Based on that idea, a fluid surplus by about $2200 \mathrm{ml}$ would be required to maintain plasma proANP during esophagectomy. Yet, it needs to be evaluated whether a perioperative fluid regime directed to maintain plasma proANP improves outcome after surgery.

\section{Abbreviations}

ANP: Atrial natriuretic peptide; ASA: American Society of Anesthesiologists classification; CBV: Central blood volume; CO: Cardiac output; HR: Heart rate; IR: Interquartile range; LR: Lactated Ringer's; MAP: Mean arterial pressure; OE: Open esophagectomy; ORC: Open cystectomy; proANP: Pro-atrial natriuretic peptide; RARC: Robot-assisted cystectomy; RE: Robot-assisted esophagectomy; SV: Stroke volume; SVR: Systemic vascular resistance

\section{Acknowledgements}

Not applicable.

\section{Funding}

This study was supported by The Danish Cancer Research Foundation (R90-A6132-14-S2).

\section{Availability of data and materials}

Data are not publicly available since another work from this study is currently being prepared for submission. However, data are available from the corresponding author on reasonable request.

\section{Authors' contributions}

All authors contributed to the design and conception of the study. RBA was responsible for perioperative monitoring of patients and acquisition of data. All authors contributed to the interpretation and analyses of data. RBS drafted the article with subsequent critical revision of its important intellectual context by all coauthors. All authors gave final approval for publication.

Competing interests

The authors declare that they have no competing interests. 


\section{Consent for publication}

Not applicable.

\section{Ethics approval and consent to participate}

The study was approved by the Scientific Ethical Committees, Capital Region, Denmark (H-2-2013-101). Oral and written consent was obtained before participation in the study.

\section{Author details}

'Department of Surgical Gastroenterology, University of Copenhagen, Rigshospitalet, Blegdamsvej 9, DK-2100 Copenhagen- $\varnothing$, Denmark. 2Department of Anesthesiology, University of Copenhagen, Rigshospitalet, Blegdamsvej 9, Copenhagen- $\varnothing$ DK-2100, Denmark. ${ }^{3}$ Department of Clinical Biochemistry, University of Copenhagen, Rigshospitalet, Blegdamsvej 9, Copenhagen- $\varnothing$ DK-2100, Denmark.

Received: 7 November 2016 Accepted: 27 January 2017

Published online: 03 February 2017

\section{References}

1. Holte K, Klarskov B, Christensen DS, Lund C, Nielsen KG, Bie P, et al. Liberal versus restrictive fluid administration to improve recovery after laparoscopic cholecystectomy: a randomized, double-blind study. Ann Surg. 2004;240: 892-9.

2. Holte K. Pathophysiology and clinical implications of peroperative fluid management in elective surgery. Dan Med Bull. 2010;57:B4156.

3. Brandstrup B, Tonnesen H, Beier-Holgersen R, Hjortso E, Ordin H, LindorffLarsen $\mathrm{K}$, et al. Effects of intravenous fluid restriction on postoperative complications: comparison of two perioperative fluid regimens: a randomized assessor-blinded multicenter trial. Ann Surg. 2003;238:641-8.

4. Krantz T, Warberg J, Secher NH. Venous oxygen saturation during normovolaemic haemodilution in the pig. Acta Anaesthesiol Scand. 2005:49:1149-56.

5. Bundgaard-Nielsen $M$, Holte $\mathrm{K}$, Secher $\mathrm{NH}$, Kehlet $\mathrm{H}$. Monitoring of perioperative fluid administration by individualized goal-directed therapy. Acta Anaesthesiol Scand. 2007;51:331-40.

6. Lobo SM, Ronchi LS, Oliveira NE, Brandao PG, Froes A, Cunrath GS, et al. Restrictive strategy of intraoperative fluid maintenance during optimization of oxygen delivery decreases major complications after high-risk surgery. Crit Care. 2011;15:R226.

7. Bundgaard-Nielsen M, Jorgensen CC, Secher NH, Kehlet H. Functional intravascular volume deficit in patients before surgery. Acta Anaesthesiol Scand. 2010;54:464-9.

8. Vogelsang TW, Yoshiga CC, Hojgaard M, Kjaer A, Warberg J, Secher NH, et al. The plasma atrial natriuretic peptide response to arm and leg exercise in humans: effect of posture. Exp Physiol. 2006:91:765-71.

9. Matzen S, Knigge U, Schutten HJ, Warberg J, Secher NH. Atrial natriuretic peptide during head-up tilt induced hypovolaemic shock in man. Acta Physiol Scand. 1990;140:161-6.

10. Schutten HJ, Kamp-Jensen M, Nielsen SL, Sztuk FJ, Engquist A, Warberg J, et al. Inverse relation between central venous pressure and the plasma concentration of atrial natriuretic peptide during positive-pressure breathing. Acta Physiol Scand. 1990;139:389-90.

11. Matzen SH. Neuroendocrine mechanisms during reversible hypovolaemic shock in humans with emphasis on the histaminergic and serotonergic system. Acta Physiol Scand Suppl. 1995;628:1-31.

12. Yandle TG, Richards AM, Nicholls MG, Cuneo R, Espiner EA, Livesey JH. Metabolic clearance rate and plasma half life of alpha-human atrial natriuretic peptide in man. Life Sci. 1986:38:1827-33.

13. Rasmussen KC, Hojskov M, Ruhnau B, Salling L, Pedersen T, Goetze JP, et al. Plasma pro-atrial natriuretic peptide to indicate fluid balance during cystectomy: a prospective observational study. BMJ Open. 2016;6, e010323.

14. Ambrus R, Svendsen LB, Secher NH, Runitz K, Frederiksen HJ, Svendsen MB, et al. A reduced gastric corpus microvascular blood flow during Ivor-Lewis esophagectomy detected by laser speckle contrast imaging technique. Scand J Gastroenterol. 2016:1-7.

15. Reed CE. Technique of Open Ivor Lewis Esophagectomy. Operative Techniques in Thoracic and Cardiovascular Surgery. 2009:14:160-75.

16. Nissen P, Van Lieshout JJ, Novovic S, Bundgaard-Nielsen M, Secher NH. Techniques of cardiac output measurement during liver transplantation: arterial pulse wave versus thermodilution. Liver Transpl. 2009;15:287-91.
17. Morgenthaler NG, Struck J, Thomas B, Bergmann A. Immunoluminometric assay for the midregion of pro-atrial natriuretic peptide in human plasma. Clin Chem. 2004;50:234-6.

18. Hunter I, Alehagen U, Dahlstrom U, Rehfeld JF, Crimmins DL, Goetze JP. $\mathrm{N}$-terminal pro-atrial natriuretic peptide measurement in plasma suggests covalent modification. Clin Chem. 2011;57:1327-30.

19. Hunter I, Rehfeld JF, Goetze JP. Measurement of the total proANP product in mammals by processing independent analysis. J Immunol Methods. 2011 370:104-10.

20. Goetze JP, Hansen LH, Terzic D, Zois NE, Albrethsen J, Timm A, et al. Atrial natriuretic peptides in plasma. Clin Chim Acta. 2015:443:25-8.

21. Roessler A, Goswami N, Haditsch B, Leoppky JA, Luft FC, Hinghofer-Szalkay $\mathrm{H}$. Volume regulating hormone responses to repeated head-up tilt and lower body negative pressure. Eur J Clin Invest. 2011;41:863-9.

22. Ewaldsson CA, Hahn RG. Kinetics and extravascular retention of acetated ringer's solution during isoflurane or propofol anesthesia for thyroid surgery. Anesthesiology. 2005;103:460-9.

23. lijima T, Brandstrup B, Rodhe P, Andrijauskas A, Svensen CH. The maintenance and monitoring of perioperative blood volume. Perioper Med (Lond). 2013:2:9.

24. de Aguilar-Nascimento JE, Diniz BN, Silveira EA, do Carmo AV, Silva RM. Clinical benefits after the implementation of a protocol of restricted perioperative intravenous crystalloid fluids in major abdominal operations. World J Surg. 2009;33:925-30

25. Kulemann B, Timme S, Seifert G, Holzner PA, Glatz T, Sick O, et al. Intraoperative crystalloid overload leads to substantial inflammatory infiltration of intestinal anastomoses-a histomorphological analysis. Surgery. 2013;154:596-603.

26. Freise $H$, Meissner A, Lauer S, Ellger B, Radke R, Bruewer M, et al. Thoracic epidural analgesia with low concentration of bupivacaine induces thoracic and lumbar sympathetic block: a randomized, double-blind clinical trial. Anesthesiology. 2008;109:1107-12.

27. Hirvonen EA, Nuutinen LS, Vuolteenaho O. Hormonal responses and cardiac filling pressures in head-up or head-down position and pneumoperitoneum in patients undergoing operative laparoscopy. Br J Anaesth. 1997;78:128-33.

28. Hirvonen EA, Poikolainen EO, Paakkonen ME, Nuutinen LS. The adverse hemodynamic effects of anesthesia, head-up tilt, and carbon dioxide pneumoperitoneum during laparoscopic cholecystectomy. Surg Endosc. 2000;14:272-7.

29. Brinkmann A, Seeling W, Wolf CF, Kneitinger E, Schonberger C, Vogt N, et al Vasopressor hormone response following mesenteric traction during major abdominal surgery. Acta Anaesthesiol Scand. 1998;42:948-56.

30. Brinkmann A, Seeling W, Rockemann M, Junge JH, Radermacher P, Wiedeck $\mathrm{H}$, et al. Changes in gastric intramucosal pH following mesenteric traction in patients undergoing pancreas surgery. Dig Surg. 1999:16:117-24.

31. Nomura Y, Funai Y, Fujimoto $Y$, Hori N, Hirakawa $K$, Hotta A, et al. Remifentanil increases the incidence of mesenteric traction syndrome: preliminary randomized controlled trial. J Anesth. 2010;24:669-74.

32. Lauridsen BK, Iversen K, Hunter I, Bay M, Kirk V, Nielsen OW, et al. ProANP plasma measurement predicts all-cause mortality in acutely hospitalised patients: a cohort study. BMJ Open. 2013:3, e003288.

33. Conway DH, Mayall R, Abdul-Latif MS, Gilligan S, Tackaberry C. Randomised controlled trial investigating the influence of intravenous fluid titration using oesophageal Doppler monitoring during bowel surgery. Anaesthesia. 2002;57:845-9.

34. Krantz T, Cai $Y$, Lauritsen $\mathrm{T}$, Warberg J, Secher NH. Accurate monitoring of blood loss: thoracic electrical impedance during hemorrhage in the pig. Acta Anaesthesiol Scand. 2000:44:598-604.

35. Harms MP, van Lieshout JJ, Jenstrup M, Pott F, Secher NH. Postural effects on cardiac output and mixed venous oxygen saturation in humans. Exp Physiol. 2003;88:611-6. 